\title{
Effect of Treadmill Exercise on Circulating Thyroid Hormone Measurements
}

\author{
Wen-Sheng Huang a Ming-Der Yu ${ }^{a}$ Meei-Shyuan Leed Cheng-Yi Cheng ${ }^{a}$ \\ Shih-Ping Yang ${ }^{b}$ Hei-Min Linda Chin ${ }^{c}$ Sing-Yung Wue \\ Departments of a Nuclear Medicine, ${ }^{b}$ Medicine, and ${ }^{c}$ Food and Nutrition, Tri-Service General Hospital, and \\ dSchool of Public Health, National Defense Medical Center, Taipei, Taiwan, ROC; 'Nuclear Medicine and \\ Medical Services (151), Department of Veterans Affairs Medical Center, Long Beach, Calif., USA
}

\section{Key Words}

Thyroid hormones - Treadmill exercise •

Hemoconcentration

\begin{abstract}
Objectives: Effects of exercise on circulating thyroid hormone (TH) values remain controversial. We sought to observe the effect of treadmill exercise on serum TH values in highly selected subjects. Methods: Twenty-six healthy male military recruits aged 23-27 (mean, 25) years were studied. All had maintained identical diet and physical activity for a week before the test. Serum samples were drawn before (baseline) and immediately, 1, 4, 24, 24 and $48 \mathrm{~h}$ after maximal exercise (on a treadmill, Bruce protocol). All subjects completed the protocol with normal ECG results. Specimens were analyzed to measure 3,3,5-triiodothyronine $\left(T_{3}\right)$, thyroxine $\left(T_{4}\right)$, free $T_{4}$ $\left(\mathrm{FT}_{4}\right)$, free $\mathrm{T}_{3}$ and thyroid-stimulating hormone (TSH) in the same assays. To determine the possible effect of hemodynamic changes, hematocrit (Hct)-adjusted data were also compared. Results: Hemoconcentration, as reflected by increased Hct, was found immediately after
\end{abstract}

exercise. No significant changes of serum mean TH values before and after exercise were found except for TSH, which increased significantly immediately after exercise (1.72 vs. baseline $1.42 \mathrm{IU} / \mathrm{l}, \mathrm{p}<0.01$ ). Values for $\mathrm{T}_{3}, \mathrm{~T}_{4}$, and TSH increased significantly immediately after exercise, as compared to other postexercise values. However, the changes became insignificant after Hct adjustment. The $\mathrm{FT}_{4}$ values showed a reciprocal increase after exercise that became significant after Hct correction. Significantly negative correlation was found between $\mathrm{FT}_{4}$ and TSH values, but these values were still well within the normal range. Conclusions: Maximal treadmill exercise does not greatly affect the determination of concentrations of circulating THs.

Copyright $@ 2004$ S. Karger AG, Basel

\section{Introduction}

Evaluation of thyroid hormone (TH) metabolism by measuring circulating $\mathrm{TH}$ values is a routine procedure for certain thyroidal and nonthyroidal illnesses including cardiovascular diseases $[1,2]$. Treadmill exercise has not

\section{KARGER \\ Fax + 41613061234 \\ E-Mail karger@karger.ch \\ www. karger.com \\ (C) 2004 S. Karger AG, Basel \\ 1011-7571/04/0131-0015\$21.00/0 \\ Accessible online at: \\ www. karger.com/mpp}

Wen-Sheng Huang, MD

Department of Nuclear Medicine, Tri-Service General Hospital

325, Section 2, Cheng-Kung Road

Taipei, Taiwan 114 (ROC)

Tel. +88628792 7374, Fax +88628792 7217, E-Mail wshuang@ms22.url.com.tw 
only become a well-established method for clinical evaluation of cardiac problems [3], but is also a popular aid for physical fitness. Available data indicated that exercise might influence a variety of metabolic and endocrine functions and lead to changed concentrations of hormone secretions in humans [4]. Notably, exercise per se may induce hemodynamic alternations, resulting in changes in circulating hormonal concentrations [5, 6]. It is therefore important to distinguish authentic concentration changes of hormones from those changes due to acute, transient exercise-induced hemoconcentration changes.

While data has been reported on effects of exercise on the TH metabolism, the results have been inconsistent or even contradictory [4, 6-11]. These divergent results may be due to differences in the intensity of work, duration of exercise, frequency and design of the training program, and to differences in gender and age of the subjects. In addition, different duration of studies, timing of sampling after exercise and methodological factors in hormonal assay and data analysis may also be responsible for the discrepancies [4, 6-10].

To avoid possible effects of the aforementioned factors, the present study was conducted to investigate the possible effect of clinical treadmill exercise on changes of circulating TH values using a well-defined group of subjects.

\section{Materials and Methods}

\section{Subjects}

A total of 27 healthy male military recruits aged 23-27 (mean, 25) years were studied. They were normotensive, free from cardiovascular disorders and underwent an identical training course. All were placed on an identical diet and maintained the same activity for a week before the test. They gave informed consent prior to participating in the study. The protocol for this study was approved by the Hospital Ethics Review Committee.

Subjects presented themselves to the laboratory between 8.00 and 9.00 a.m. after a regular meal containing 650-790 kcal (carbohydrate, $100-130 \mathrm{~g}$; fat, $20 \mathrm{~g}$ and protein, $20-25 \mathrm{~g}$ ) at $7.00 \mathrm{a} . \mathrm{m}$. The energy and macronutrient values of the lunch and dinner were similar to that of the breakfast. Serum samples were drawn from an antecubital vein before (baseline) and immediately after, 1, 4, 24, and $48 \mathrm{~h}$ of the graded treadmill exercise testing. The exercise protocol was based on the standard Bruce protocol [3]. Briefly, it began at $1.7 \mathrm{mph}$ and a $10 \%$ grade reaching approximately 4 metabolic equivalents [METs, multiples of $\mathrm{O}_{2}$ consumption of $3.5 \mathrm{ml} /(\mathrm{kg} \times \mathrm{min})$ ] in sitting position with increments in speed and grade every $3 \mathrm{~min}$. The protocol allows total-body aerobic work to increase at approximately 1 MET for every minute of exercise. All subjects completed the protocol with normal ECG results. Immediately after exercise blood samples were obtained within 2 min of termination of the exercise. A total of 162 blood specimens were collected for the study. After sepa- ration, samples were stored at $-70^{\circ} \mathrm{C}$ and were analyzed in the same assays for 3,3',5-triiodothyronine $\left(\mathrm{T}_{3}\right)$, thyroxine $\left(\mathrm{T}_{4}\right)$, free $\mathrm{T}_{4}\left(\mathrm{FT}_{4}\right)$, free $\mathrm{T}_{3}\left(\mathrm{FT}_{3}\right)$ and thyroid-stimulating hormone (TSH).

\section{TH Assays}

Serum concentrations of $\mathrm{T}_{3}, \mathrm{~T}_{4}$ (Diagnostic Products Corp., Calif., USA), $\mathrm{FT}_{4}, \mathrm{FT}_{3}$ (Clinical Assays, Incstar Corp., Stillwater, Minn., USA) and TSH (Diagnostic Products Corp.) were determined by radioimmunoassay or ultrasensitive immunoradiometric assay. Normal ranges were $58-161 \mathrm{nmol} / 1$ for $\mathrm{T}_{4}, 1.3-2.8 \mathrm{nmol} / 1$ for $\mathrm{T}_{3}, 9$ $26 \mathrm{pmol} / 1$ for $\mathrm{FT}_{4}, 2.3-7.7 \mathrm{nmol} / 1$ for $\mathrm{FT}_{3}$, and $0.3-5.0 \mathrm{mU} / \mathrm{l}$ for $\mathrm{TSH}$. The analytical sensitivity of the TSH assay was $0.03 \mathrm{mU} / 1$. Averaged interassay and intra-assay coefficients of variation for each assay were as follows: 6.1 and $4.1 \%$ for $\mathrm{T}_{4}, 5.8$ and $4.5 \%$ for $\mathrm{T}_{3}, 6.2$ and $6.8 \%$ for $\mathrm{FT}_{4}, 7.7$ and $6.1 \%$ for $\mathrm{FT}_{3}$, and 3.0 and $1.5 \%$ for $\mathrm{TSH}$. Concentrations of circulating cortisol, adrenocorticotropic hormone (ACTH) and aldosterone at certain set time points were also measured using commercial methods. The accuracy and reproducibility of these tests were ensured by an in-house quality control program and by participation in the College of American Pathologists' Basic Ligand Assay quality assurance program.

\section{Hematological Examinations}

To investigate hemoconcentration, hematocrit (Hct), hemoglobin $(\mathrm{Hb})$ and red blood cell (RBC) counts were measured at each set time point by a routine automatic method. The Hct-adjusted THs were calculated from values of individual TH parameters divided by the corresponding Hct values to observe any possible influence of exercise-induced hemodynamic changes on circulating $\mathrm{TH}$ measurements [5].

\section{Statistics}

All data were expressed as the group mean \pm SEM. Owing to the non-normality of the distribution of TH log transformation of the values was applied to make it nearly normal. Using generalized estimating equation methods with an identity link function, we modeled the change in TH values over time by contrasting with level immediately after exercise with or without adjusting for Hct between the repeated measures [12]. Linear regression analysis was used to test for association between $\mathrm{FT}_{4}$ and TSH levels. A p value of less than 0.05 was considered statistically significant.

\section{Results}

Results of peripheral TH measurements pre- (baseline) and postexercise are given in table 1. Hemoconcentration was found immediately after exercise, as reflected by increases of $\mathrm{Hct}, \mathrm{Hb}$ values and $\mathrm{RBC}$ counts (table 2). Immediately after exercise circulating ACTH and aldosterone levels increased significantly compared to the baseline values. ACTH and cortisol values immediately after exercise were also found to be significantly higher than those a longer period after exercise (table 1). Except for $\mathrm{TSH}$, no significant change of $\mathrm{TH}$ values immediately after exercise compared to the baseline was found. The $\mathrm{T}_{3}, \mathrm{~T}_{4}$ and TSH values immediately after exercise in- 
Table 1. Serum values of peripheral hormones before and after treadmill exercise

\begin{tabular}{|c|c|c|c|c|c|c|}
\hline & Pre & Imm & $1 \mathrm{~h}$ & $4 \mathrm{~h}$ & $24 \mathrm{~h}$ & $48 \mathrm{~h}$ \\
\hline $\begin{array}{l}\mathrm{T}_{3} \\
(1.3-2.8 \mathrm{nmol} / \mathrm{l})\end{array}$ & $1.72 \pm 0.12$ & $1.83 \pm 0.06$ & $1.59 \pm 0.06^{* *}$ & $1.51 \pm 0.06^{* *}$ & $1.51 \pm 0.05^{* *}$ & $1.56 \pm 0.09 * *$ \\
\hline $\begin{array}{l}\mathrm{T}_{4} \\
(58-161 \mathrm{nmol} / \mathrm{l})\end{array}$ & $93.3 \pm 3.2$ & $97.9 \pm 3.4$ & $90.1 \pm 3.5^{* *}$ & $90.5 \pm 4.3^{* *}$ & $91.4 \pm 2.7^{*}$ & $89.8 \pm 3.4^{* *}$ \\
\hline $\begin{array}{l}\text { TSH } \\
(0.3-5.0 \mathrm{IU} / 1)\end{array}$ & $1.40 \pm 0.12 * *$ & $1.72 \pm 0.14$ & $1.30 \pm 0.09 * *$ & $1.13 \pm 0.09^{* *}$ & $1.08 \pm 0.08^{* *}$ & $1.06 \pm 0.09 * *$ \\
\hline $\begin{array}{l}\mathrm{FT}_{3} \\
(2.3-7.7 \mathrm{pmol} / \mathrm{l})\end{array}$ & $3.4 \pm 0.2$ & $3.4 \pm 0.2$ & $3.2 \pm 0.2$ & $3.1 \pm 0.1$ & $3.0 \pm 0.2^{*}$ & $3.2 \pm 0.3$ \\
\hline $\begin{array}{l}\mathrm{FT}_{4} \\
(9.0-25.7 \mathrm{pmol} / \mathrm{l})\end{array}$ & $25.4 \pm 0.6$ & $25.0 \pm 0.6$ & $24.3 \pm 0.6$ & $24.7 \pm 0.5$ & $25.2 \pm 0.5$ & $25.7 \pm 0.4$ \\
\hline $\begin{array}{l}\text { Aldosterone } \\
(102-664 \mathrm{nmol} / \mathrm{l})\end{array}$ & $418 \pm 36^{* *}$ & $631 \pm 36$ & $606 \pm 36$ & $374 \pm 33^{* *}$ & $407 \pm 30^{* *}$ & $392 \pm 28^{* *}$ \\
\hline $\begin{array}{l}\text { Cortisol } \\
(69-690 \mathrm{nmol} / \mathrm{l})\end{array}$ & $327 \pm 22$ & $331 \pm 22$ & $271 \pm 21^{*}$ & $193 \pm 16^{* *}$ & $240 \pm 16^{* *}$ & $218 \pm 15^{* *}$ \\
\hline $\begin{array}{l}\mathrm{ACTH} \\
(2.0-11.5 \mathrm{pmol} / \mathrm{l})\end{array}$ & $11.2 \pm 1.0^{* *}$ & $31 \pm 4.9$ & $8.0 \pm 0.7 * *$ & $6.6 \pm 0.6^{* *}$ & $7.2 \pm 0.5^{* *}$ & $7.5 \pm 0.4^{* *}$ \\
\hline $\mathrm{T}_{3} / \mathrm{Hct}$ & $0.037 \pm 0.002$ & $0.037 \pm 0.001$ & $0.035 \pm 0.001$ & $0.034 \pm 0.001$ & $0.034 \pm 0.001$ & $0.036 \pm 0.003$ \\
\hline $\mathrm{T}_{4} / \mathrm{Hct}$ & $2.059 \pm 0.064$ & $1.931 \pm 0.064$ & $2.059 \pm 0.077$ & $2.059 \pm 0.103$ & $2.188 \pm 0.064$ & $2.059 \pm 0.077$ \\
\hline $\mathrm{TSH} / \mathrm{Hct}$ & $0.03 \pm 0.003$ & $0.03 \pm 0.003$ & $0.03 \pm 0.002$ & $0.02 \pm 0.002$ & $0.03 \pm 0.002$ & $0.02 \pm 0.002$ \\
\hline $\mathrm{FT}_{3} / \mathrm{Hct}$ & $0.075 \pm 0.005$ & $0.071 \pm 0.005$ & $0.069 \pm 0.003$ & $0.072 \pm 0.003$ & $0.072 \pm 0.005$ & $0.074 \pm 0.006$ \\
\hline $\mathrm{FT}_{4} / \mathrm{Hct}$ & $0.553 \pm 0.013^{* *}$ & $0.502 \pm 0.013$ & $0.541 \pm 0.013^{* *}$ & $0.566 \pm 0.013^{* *}$ & $0.579 \pm 0.013^{* *}$ & $0.592 \pm 0.013^{* *}$ \\
\hline
\end{tabular}

Values are means \pm SEM; Pre = pre-exercise (baseline); $\mathrm{Imm}=$ immediately after exercise; $1,4,24$, and $48 \mathrm{~h}=1,4,24$, and $48 \mathrm{~h}$ after exercise; T3/Hct and TSH/Hct $=$ Hct-corrected T3 and TSH; $*$ p $<0.05$ vs. Imm; $* * p<0.01$ vs. Imm.

Table 2. The values of $\mathrm{Hct}, \mathrm{Hb}$ and $\mathrm{RBC}$ counts before and after treadmill exercise

\begin{tabular}{lllllll}
\hline & Pre & Imm & $1 \mathrm{~h}$ & $4 \mathrm{~h}$ & $24 \mathrm{~h}$ & $48 \mathrm{~h}$ \\
\hline Hct $(42-52 \%)$ & $46.4 \pm 0.5^{* *}$ & $49.8 \pm 0.5$ & $44.7 \pm 0.5^{* *}$ & $44.1 \pm 0.4^{* *}$ & $43.8 \pm 0.4^{* *}$ & $43.3 \pm 0.4^{* *}$ \\
$\mathrm{Hb}(14-18 \mathrm{mg} / \mathrm{dl})$ & $15.7 \pm 0.2^{* *}$ & $16.6 \pm 0.2$ & $15.3 \pm 0.2^{* *}$ & $15.1 \pm 0.2^{* *}$ & $14.9 \pm 0.2^{* *}$ & $14.9 \pm 0.2^{* *}$ \\
RBC $(4.7-6.1 \mathrm{M} / \mathrm{dl})$ & $5.27 \pm 0.09^{*}$ & $5.56 \pm 0.09$ & $5.12 \pm 0.08^{* *}$ & $5.06 \pm 0.06^{* *}$ & $4.99 \pm 0.08^{* *}$ & $4.96 \pm 0.09^{* *}$
\end{tabular}

Data are expressed as mean $\pm \mathrm{SEM}$; Pre = pre-exercise (baseline); Imm = immediately after exercise; $1,4,24$, and $48 \mathrm{~h}=1,4,24$, and $48 \mathrm{~h}$ after exercise; $* \mathrm{p}<0.05$ vs. Imm; $* * \mathrm{p}<0.01$ vs. Imm.

creased significantly compared to those of other postexercise groups (fig. 1). Such changes became insignificant when data were adjusted with the corresponding Hct values. Circulating $\mathrm{FT}_{3}$ and $\mathrm{FT}_{4}$ values were relatively stable in response to treadmill exercise. Notably, there was a reciprocal increase of serum $\mathrm{FT}_{4}$ values after exercise, which reached statistical significance after Hct correction (fig. 2). A significantly negative correlation between $\mathrm{FT}_{4}$ and TSH values was found $(\mathrm{p}=0.03)$. However, these changes were all within the reported normal ranges for reference values. 


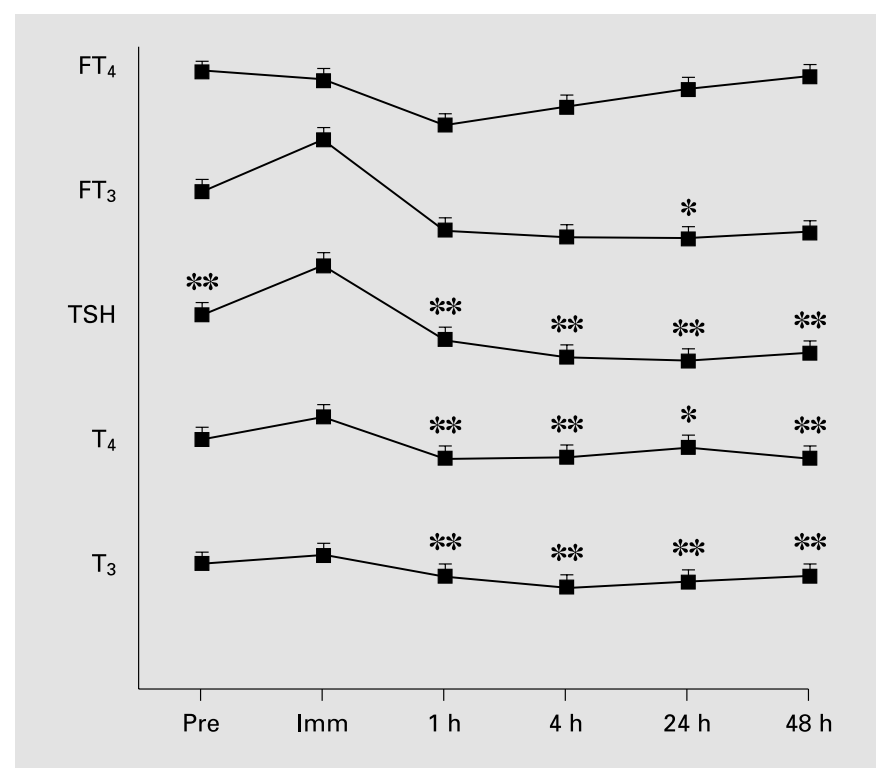

Fig. 1. Circulating $\mathrm{T}_{3}, \mathrm{~T}_{4}, \mathrm{TSH}, \mathrm{FT}_{3}$, and $\mathrm{FT}_{4}$ values in healthy men before and immediately, 1, 4, 24 and $48 \mathrm{~h}$ after treadmill exercise. Abbreviations are defined in table 1 .

\section{Discussion}

Hemoconcentration, as reflected by significant increases of $\mathrm{Hct}, \mathrm{Hb}$, and RBC counts, was found in the present study at the set point immediately after maximal treadmill exercise. Significant changes of circulating $T_{3}$, $\mathrm{T}_{4}$ and TSH values after acute exercise appeared to be due to plasma volume alternations because such changes became trivial after Hct adjustment. Since the changes remain well within the normal range, they may not significantly affect the interpretation of in vitro thyroid function tests in routine practice.

The cardiovascular system is a main target of THs. Heart problems may be derived from imbalanced TH action [1]. Treadmill exercise has become a standard protocol to evaluate cardiac performance and has served as a popular tool for physical fitness. In vitro thyroid function tests have also been used widely in routine clinical applications. However, there is no consensus as to whether treadmill exercise affects measurements of circulating TH $[4,6,9$, 10]. In this study the subjects we recruited were all healthy young men who invariably completed the exercise protocol with normal ECG. The identical gender, diets, and daily activity together with the narrow age range of the subjects enabled us to exclude, at least in part, individual variation.

Exercise per se can cause hemoconcentration [5]. However, the hemodynamics return to baseline within min-

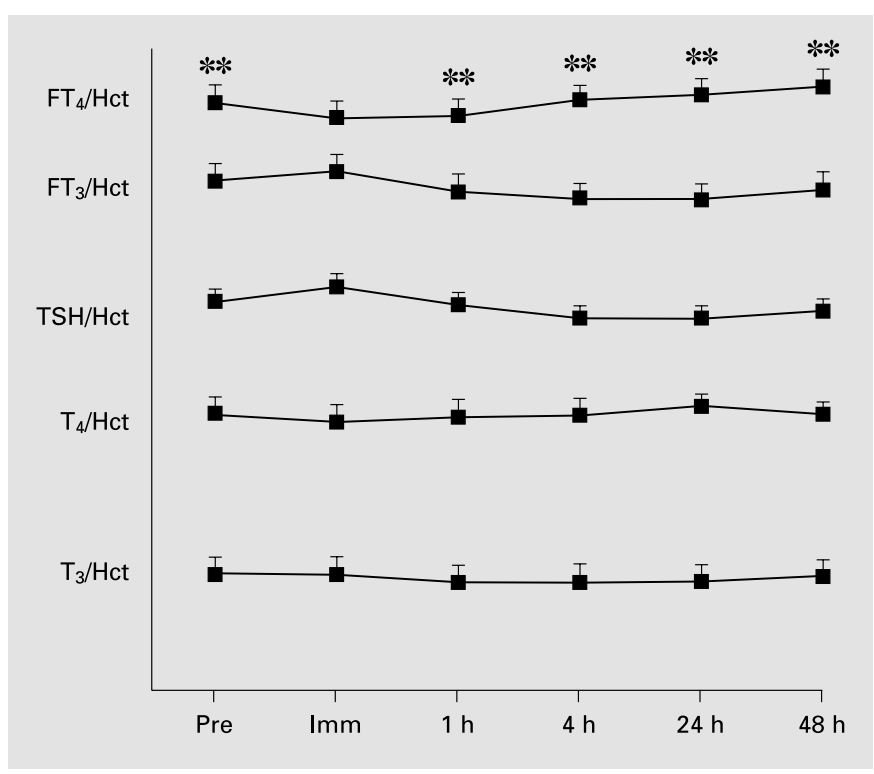

Fig. 2. Hct-divided circulating $T_{3}, T_{4}, T S H, F_{3}$, and $F_{4}$ values in healthy men before and immediately, 1, 4, 24 and $48 \mathrm{~h}$ after treadmill exercise. Abbreviations are defined in table 1.

utes following termination of exercise [18]. Measurements of changes in hormone values after exercise may reflect only acute transcapillary movements of water, which resolve shortly after exercise ceases [5, 6, 13]. Therefore measurements of circulating hormones over periods covering such acute changes must be approached with caution. In this regard, measurement of Hct was thought to be a suitable way to evaluate hemoconcentration [5].

In this study, circulating TSH levels increased shortly after treadmill exercise followed by a significant decrease until the end of the study period. The hemoconcentration results contradicted some reports that no apparent Hct changes were found $[11,14]$. However, our results were consistent with other reports [7, 9, 13-16] suggesting that hemoconcentration could be a cause of changes in circulating TSH. High serum levels of cortisol generated by the stress procedure might also contribute to the post-stress (treadmill exercise) depression of TSH levels [7]. Serum levels of ACTH and cortisol were higher immediately after exercise than those $4 \mathrm{~h}$ after exercise (31 vs. $6.6 \mathrm{pmol} / \mathrm{l}$ for $\mathrm{ACTH}$, and $331 \mathrm{vs.} 193 \mathrm{nmol} / \mathrm{l}$ for cortisol; $\mathrm{p}<0.01$, respectively). In addition, we found significant increases of aldosterone immediately and $1 \mathrm{~h}$ after exercise $(631 \pm 36$ and $606 \pm 36$ vs. baseline, $418 \pm 27 \mathrm{nmol} /$ $1 ; \mathrm{p}<0.01$, respectively), which might cause additional increases of plasma volume as exercise ceased [17]. While 
the interplay between TSH, cortisol and aldosterone still needs further clarification, hemodynamic changes related to acute exercise appeared to be responsible for the alteration of TSH values because such changes became insignificant after Hct correction.

The significant changes of $\mathrm{T}_{3}$ and $\mathrm{T}_{4}$ values after exercise also became insignificant after Hct correction, a further indication of plasma volume changes in response to exercise. Physical exercise has been reported to stimulate the peripheral deiodination of $\mathrm{T}_{4}[8,10]$ and an increased uptake of $\mathrm{T}_{4}$ in the liver during exercise [18]. Moreover, both cortisol and catecholamine actions initiated by exercise will also stimulate peripheral $\mathrm{T}_{4}$ deiodination [19, 20]. Whether the accelerated deiodination resulted in the increase in $\mathrm{T}_{3}$ and minimal decrease in $\mathrm{FT}_{4}$ values observed immediately after exercise remains to be clarified. Curiously, in this study, there appeared to be a reciprocal change between $\mathrm{FT}_{4}$ and $\mathrm{TSH}$. The increased $\mathrm{FT}_{4}$ value after exercise became significant after Hct correction. Sowers et al. [7] claimed that the increased $\mathrm{FT}_{4}$ might partially account for the postexercise decrease of TSH. In the present study, we also found a significant correlation between circulating $\mathrm{FT}_{4}$ and $\mathrm{TSH}(\mathrm{p}=0.03)$. In spite of the aforementioned physiological relevance, it appeared that such interactions would be quite minor in our subjects under treadmill exercise, a finding in agreement with most previous studies [8].
While published reports showed effects of exercise on measurements of circulating $\mathrm{TH}$, our current observations using treadmill exercise found that the variations were marginal. It is unlikely that such small changes, that may also reflect normal fluctuations during the day, deserve to be taken into consideration for daily clinical practice, or for follow-up of patients receiving either antithyroid drug treatment for hyperthyroidism or $\mathrm{T}_{4}$ therapy at replacement or suppressive doses.

\section{Conclusion}

Our results indicate that, for normal clinical practice, a maximal treadmill exercise protocol may not affect the determination of concentrations of circulating TH. However, for those serum $\mathrm{TH}$ values that need to be measured precisely, it is suggested that samples should not to be taken immediately after exercise.

\section{Acknowledgments}

The authors thank Ms. Mei-Rong Chang for technical support and Miriam Wang for administrative assistance. This work was supported by the National Science Council under grant NSC 89-2314B-016-078-M08.

\section{References}

1 Levey GS: Thyroid and the heart; Introduction. Am J Med 1990;88:625.

2 Klein I, Ojamaa K: Thyroid hormone: Targeting the heart. Endocrinology 2001;142:11-12.

3 Bruce RA: Exercise testing of patients with coronary disease: Principles and normal standards for evaluation. Ann Clin Res 1973;3:323-332.

4 Hashimoto T, Migita S, Matsubara F: Response of thyrotropin and free thyroid hormones to gated exercise in normal subjects. Endocr J 1986;33:735-741.

5 van Beaumont W: Evaluation of hemoconcentration from hematocrit measurements. J Appl Physiol 1972;32:712-713.

6 Smallridge RC, Whorton NE, Burman KD, Ferguson EW: Effects of exercise and physical fitness on the pituitary-thyroid axis and on prolactin secretion in male runners. Metabolism 1985;34:949-954.

7 Sowers JR, Raj RP, Hershman JM, Carlson HE, McCallum RW: The effect of stressful diagnostic studies and surgery on anterior pituitary hormone release in man. Acta Endocrinol (Kbh) 1977;86:25-32.

8 Opstad PK, Falch D, Okedalen O, Fonnum F, Wergeland R: The thyroid function in young men during prolonged exercise and the effect of energy and sleep deprivation. Clin Endocrinol 1984;20:657-659.

9 Krotkiewski M, Sjostrom L, Sullivan L, Lundberg PA, Lindstedt $\mathrm{G}$, Wetterqvist $\mathrm{H}$, Bjorntorp P: The effect of acute and chronic exercise in thyroid hormones in obesity. Acta Med Scand 1984;216:269-275.

10 Irvine $\mathrm{CH}$ : Effect of exercise on thyroxine degradation in athletes and non-athletes. $\mathrm{J}$ Clin Endocrinol Metab 1968;28:942-948.

11 Siddiqui AR, Hinnefeld RB, Dillon T, Judson WE: Immediate effects of heavy exercise on the circulating thyroid hormones. Br J Sports Med 1983; 17:180-183.

12 Liang KY, Zeger SL: Longitudinal data analysis using generalized linear models. Biometrika 1972;73:13-22.

13 Refsum HW, Stromme SB: Serum thyroxine, tri-iodothyronine and thyroid stimulating hormone after prolonged physical exercise. Scand J Clin Invest 1979;39:455-459.

14 Galbo H, Hummer L, Peterson IB, Christensen NJ, Bie N: Thyroid and testicular hormone responses to graded and prolonged exercise in man. Eur J Appl Physiol 1977;36:101-106.
15 Terjung RL, Tipton CM: Plasma thyroxine and thyroid-stimulating hormone levels during submaximal exercise in humans. Am J Physiol 1971;220:1840-1845.

16 Schmid P, Wolf W, Pilger E, Schwaberger E, Pessenhofer G, Pristautz H, Leb G: TSH, T3, rT3, and fT4 in maximal and submaximal physical exercise. Eur J Appl Physiol 1982;48: 31-39.

17 Williams GH, Braunwald E: Endocrine and nutritional disorders and heart disease; in Braunwald E (ed): Heart Disease. A Textbook of Cardiovascular Medicine, ed 4. Philadelphia, Saunders, 1992, pp 1837-1840.

18 Terjung RL, Winder WW: Exercise and thyroid hormone. Med Sci Sports Exerc 1975;7: 20-26.

19 Chopra IJ, Williums DE, Orgiazzi J, Solomon DH: Opposite effects of dexamethasone on serum reverse T3 and T3. J Clin Endocrinol Metab 1975;41:911-920.

20 Nauman A, Kaminski T, Herbaczynska-Cedro $\mathrm{K}$ : In vivo and in vitro effects of adrenaline on conversion of thyroxine to triiodothyronine and to reverse-triiodothyronine in dog liver and heart. Eur J Clin Invest 1980;10:189-192. 